\title{
The Networked Individualism Approach for Understanding The Importance of ICT In Mainland China
}

\author{
Zhengke Fu1, Mengsi Yan2 \\ 1Department of art and communication, Ningbo institue of technology, \\ Zhejiang University, Zhejiang, 315000, China \\ 2Department of Humanity, Ningbo Dahongying University, Zhejiang, \\ 315000, China
}

\begin{abstract}
At present, most of the researches on relationship between ICT and social impact are focused on specific communication technology. This paper discusses the impact of ICT on social life with the perspective of networked individualism. In order to answer the problem efficiently, we present the relationship between social network, ICT and loneliness. In the proposed model, firstly, ICT is used to maintain different social relationships. As a result, people will combine EMAIL, IM, SNS to maintain their social network. In addition, the larger the mediated social network, the lower UCLA loneliness. Whats more, the more friends in the EMAIL, IM, SNS friends, the lower UCLA loneliness. Finally, the more family members in the EMAIL, IM, SNS, the higher UCLA loneliness, and the normal relationship in the media has no effect on UCLA. The result from 4 emperical studys indicates the importance of ICT for peoples life.
\end{abstract}

Keywords:Networked individualism social network ICT loneliness

\section{Introduction}

Basing on the existing theories, two question is waiting to be answered questions: First, media do extends humanity, but except few studies[9-12], Existing studies have not answer how ICT will extend modern social relations? Secondly, 
although the existing Communication analyzes the impact of ICT use on the wellbeing, social support, depression[13], but hasn't analyzinig how ICT might affect loneliness, which is an important social psychological phenomenon the modern people facing nowdays.

In this paper, based on the existing theory and research methods[2] we propose a networed individualism approach to explore the relationship between social network, ICT and loneliness. firstly, ICT is used to maintain different social relationships. As a result, people will combine EMAIL, IM, SNS to maintain their social network. In addition, the larger the mediated social network, the lower UCLA loneliness. Whats more, the more friends in the EMAIL, IM, SNS friends, the lower UCLA loneliness. Finally, the more family members in the EMAIL, IM, SNS, the higher UCLA loneliness, and the normal relationship in the media has no effect on UCLA.. We shows that the impact of the new media is more and more important today, we need to pay attention to the dual effect of the new media, which proposed new requirements for the media literacy for us.

The paper is organized as follows. In the next section, we propose the model that we research in this paper, and some definitions and assumptions are given. In Section 3, the impact of social network to ICT usage based on media affordace theory is presented. Section 4 presents ICT mediated social network impact on loneliness based on social capital theory. In Section 5, the cross-sectional method is used to illustrate the impacts of ICT. Finally, we conclude our paper in section 6.

\section{Discussed problems}

The discussed model is given as follow:

$$
\text { UCLAloneliness }=a+b_{1} x_{1}+b_{2}(\text { female })+b_{3}(\text { education })+b_{4}(\text { age })
$$

Some basic concepts associated with the problem are presented as follows Mediated social networks:

This is $\mathrm{X} 1$,which is the independent variable of interest. The mediated social network represents the quality and quantity of social relationship we carried out through ICT, like IM, SNS and email.

UCLA loneliness:

This is $\mathrm{Y}$, which is the dependent variable of interest. The UCLA represents the loneliness situation of people.

Background variables:

They are key demographic variables we added to control. The demographic variables includes sex, age and education.

\section{Definition 1}

For mediated social network, if the following conditions are satisfied:

i) people use ICT to connect with different type of social relationships; 
Then, we called such social network as the mediated social network

\section{Definition 2}

For loneliness, if people answer the UCLA questionnaire, then we get his extent of loneliness.

Two assumptions are given as follows:

i) Different ICT is used to mediate different social network

ii) The mediated social network might significantly affect UCLA

\section{3. media affordance: ICT as an extension of social networks}

\subsection{The social affordance of media}

Media affordance as the key concept of networked individualism, explains how media to become an extension of the social networks. Media affordance means: an individual would select the appropriate media for social interaction,according to the function provided by the media and the situation of social interaction [14]. Affordance emphasized two points: first, the technology has its inherent characteristics, and secondly, these technical features will affect people's decision on how to use these media.

\subsection{Media as the extention of social network}

People need to select different ICTs to contact with each other. Existing research indicates that different ICT provide different function when people need communicate with someone. e-mail enables asynchronous communication to occur, so that people can have enough time to organize their information; instant messag tools not only support asynchronous communication, but also supports synchronous communication.As mobile phones increasingly embedding different communication oriented software,people are allowed to use different communication tools for emergency contact, miniature cooperation, emotional support becomes possible[15].

ICT carries different types of social relations. The diversity of social relations determines people will use different types of media to maintain social relations: on one hand, people use all kinds of media keep in touch with the social network, on the other hand,basing on the type of their friends, they migh choose specific tools to communicate with specific relationship[4, 16, 17].Some scholars have pointed out that, in addition to face to face, most of the participants will try to use all the media to maintain their social relations, as people use instant messaging or social networking software to maintain weak ties. An South Korea's research indicates that people tend to use the phone and face to face interaction to maintain strong community relations

Social networking is the sum of the individual social relations, which is a relatively stable structural elements. So how social networks affect ICT use? The problem in the United States through a nationwide empirical test, but in Asia, only South Korea, Singapore and Taiwan study the question based on a particular 
group rather than a national investigation.So, in China, how migh the status of social networks affect the use of ICT it?

\section{Social capital, ICT use and Loneliness}

The concept of networked individualism, on one hand emphasize the structural impact of social relations on the the use of ICT, on the other hand focus on how ICT can be used to enhance the social capital. When the ideal of social relations can not be obtained, it may face a higher risk of ill feeling out of control. In Durkheim's book "On suicide" it has pointed out that one important reason causes suicide is lack of ideal social relationship which would cause loneliness[22].in this study, Loneliness is conceptualized as a negative experience arising from lack of ideal social relations in the social network.

Media and social networks together have an impact on loneliness. Keep in touch with people in social networks through the use of different types of media could significantly affect social capital and happiness. IM, SNS, e-mail as the primary network communication tools, has a high penetration rate in China (CNNIC, 38th Statistical Report on China Internet Network Information Center, 2016.7) can be speculated that the three social media networks as intermediaries may have a significant impact on individual loneliness.

\section{Data gathering and analysis}

In order to illustrate the feasibility and effectiveness of the theory, we construct two studies according to examples in literature[9-12]. We solve them by two different approaches. The first is the approach proposed in this paper, and the second approach is the same as the first one except using the regression function to answer the question how might mediated social network impact loneliness.

The measurement of variables are shown as follows:

The first part of the questionnaire asked participants to answer background information

The second part of the questionnaire used to obtain data mediation of social networks. According Tesung's research, mediation of social networks can be measured by two indicators: one is the size of social networks, the data is obtained by adding the total number of social networks in each media; the other is the intensity of social network relations, by getting the data of relationship type and the closeness of the relationship, we can calculate the strength of ties in the specific media. By modifying Tesung's mediated social networks questionnaire, the data of EMAIL,IM,SNS mediated social networks could be obtained through participants recalling the social relations ICT carried last week.

UCLA loneliness. By correcting UCLA loneliness questionnaire by Likert scale measuring loneliness condition of the individual, four topics ranging from 1 (strongly disagree) to 5 (strongly agree) score, the higher the score the higher the feeling of loneliness. To test the stability and the intrinsic validity of the questionnaire, the factor analysis and reliability analysis had been used. The 
KMO value (.826), is greater than 0.8 , and therefore the questionnaire was suitable for factor analysis. Via factor analysis, factor loading amount of each question item 0.6, so each question item has good convergent validity. Eigenvalues 1.0 to arrive at a factor of the total variance explained by the amount of $(73.123) \%$. Internal consistency coefficient (Cronbachs' $\alpha$ ) is (.877), greater than 0.7 .The correlation between scale item is is greater than 0.3 , project-related amended greater than 0.5 .Specific scale entry in Table 1 and Table 2.

Table 1: UCLA factor analysis

\begin{tabular}{|l|c|}
\hline & Factors \\
\hline UCLA1 When I need to, no one to help me & .69 \\
\hline UCLA2 I'm missing my partner & .74 \\
\hline UCLA3 feel left out & .77 \\
\hline UCLA4 I feel isolated & .72 \\
\hline
\end{tabular}

Table 2: correlation between scale items

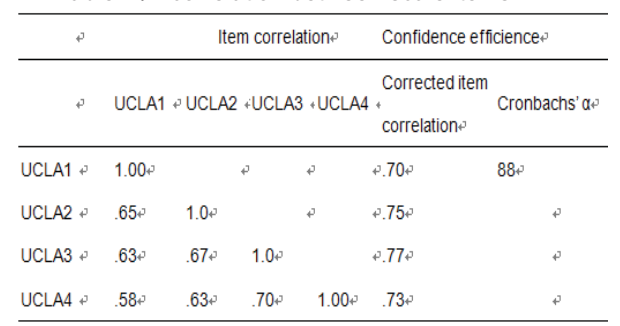

The mediated social network are shown as follows:

Table 3 the mediated social network

\begin{tabular}{|c|c|c|c|c|c|}
\hline \multirow{2}{*}{$\begin{array}{l}\text { Mediated } \\
\text { network }\end{array}$} & \multicolumn{5}{|c|}{ mediated social network } \\
\hline & relationship & number & percentage & mean & std \\
\hline \multirow{4}{*}{ EMAIL } & Family & 2110 & 29.00 & 2.13 & 0.05 \\
\hline & $\begin{array}{l}\text { Close } \\
\text { friend }\end{array}$ & 2625 & 36.00 & 2.64 & 0.06 \\
\hline & $\begin{array}{l}\text { Nomal } \\
\text { friend }\end{array}$ & 2577 & 35.00 & 2.59 & 0.07 \\
\hline & Family & 2711 & 30.00 & 2.73 & 0.05 \\
\hline \multirow[t]{3}{*}{ IM } & $\begin{array}{l}\text { Close } \\
\text { friend }\end{array}$ & 3270 & 35.00 & 3.29 & 0.06 \\
\hline & $\begin{array}{l}\text { Nomal } \\
\text { friend }\end{array}$ & 3262 & 35.00 & 3.28 & 0.07 \\
\hline & Family & 2455 & 29.00 & 2.47 & 0.06 \\
\hline \multirow[t]{2}{*}{ SNS } & $\begin{array}{l}\text { Close } \\
\text { friend }\end{array}$ & 3098 & 36.00 & 3.11 & 0.07 \\
\hline & $\begin{array}{l}\text { Nomal } \\
\text { friend }\end{array}$ & 3017 & 35.00 & 3.03 & 0.07 \\
\hline
\end{tabular}

As can be shown in the table, Chinese mainland residents mainly use instant messaging tool to maintain social relationships. Survey results show that the number of people using the instant messaging tools of social relations is 9243 , email and social media related number is 7312 and 8570 respectively. Mean number of social relations in each media as follows: people use IM to maintain about 9 people on average, while the number of social relationships through EMAIL and SNS is 7 and 8 respectively(Table 3 ). 
The Numerical mean number of social relationships are significantly different EMAIL $\left(x^{2}=66.41, d f=2, p<.00\right)$, IM $\left(x^{2}=66.66, d f=2, p<.00\right)$, SNS $\left(x^{2}=85.86, d f=2, p<.00\right)$. The mean number of social network data shows the characteristics of media diversity: people will focus on the use of three different types of ICT with family, friends and the general relationship. Strong relationship between the three mediation differs, the number of friends is larger than the family relations $\left(x^{2}=181.20, d f=1, p<.00\right)$.

Table 4 The impact of mediated social network on UCLA loneliness

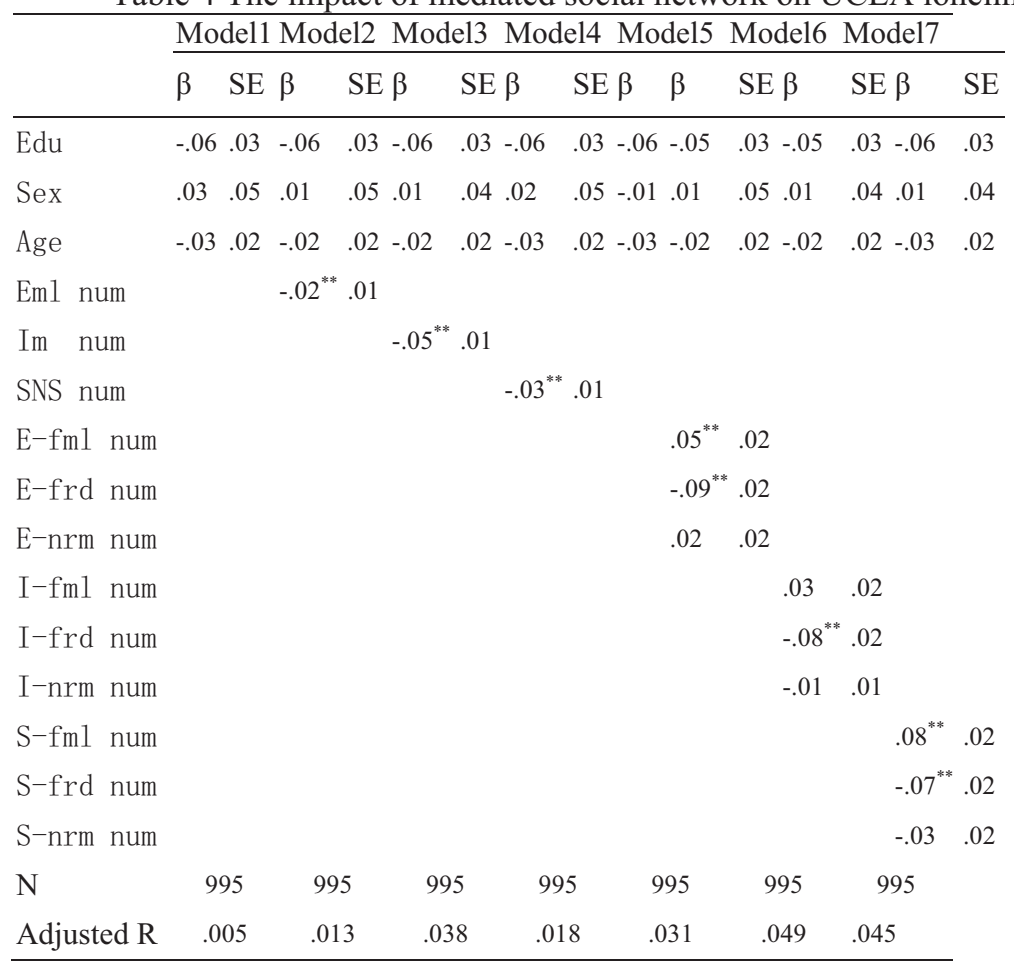

As can be seen from table 4, we use the social network in the email, instant messaging and social media as predictors.

Model 2 to 4 show email, instant messaging network, social media network negativly impact UCLA Loneliness significant, which shows that the larger social networks in email, instant messaging and social media networks, the lower UCLA loneliness.

Model 5 to 7 measuring link between the different types of social relations in each media channels and loneliness. It shows that the more close friends in email,, instant messaging networks, social media networks, the lower UCLA Loneliness, while the Internet, the more family member in social media networks, The higher UCLA loneliness. 


\section{Conclusions}

In the proposed theory framework, the ambigious problem is transofrmed into the realtionship between the social network, communication channel and loneliness. The current study points out the importance of the ICT for people nowdasy. The major advantage of this study is it takes ICT not seperately, which could get a more grand picture of ICT significance. Hence, it can be used to give modern people more clear understanding of how to use ICT properly, and shows the necessity of media literacy educeation.

\section{Acknowledgements}

The research work was supported by Zhejiang Federation of Humanities and Social Sciences Circles under Grant No. 2015N033, Zhejiang Provincial Department of Culture under Grant No. 2011-z-756 and Zhejiang Provincial Department of education.

\section{References}

1. Park, R.E., The city: Suggestions for the investigation of human behavior in the city environment. The American Journal of Sociology, 1915. 20(5): p. 577-612.

2. Boase, J., Personal networks and the personal communication system: Using multiple media to connect. Information, communication \& society, 2008. 11(4): p. 490-508.

3. Wellman, B., Little boxes, glocalization, and networked individualism, in Digital cities II: Computational and sociological approaches. 2001, Springer. p. 10-25.

4. Cummings, J., J. Lee, and R. Kraut, Communication technology and friendship during the transition from high school to 
college. Computers, phones, and the Internet: Domesticating information technology, 2006: p. 265-278.

5. Anderson, B. and K. Tracey, Digital Living The Impact (or Otherwise) of the Internet on Everyday Life. American behavioral scientist, 2001. 45(3): p. 456-475.

6. Ofcom, Social networking: A quantitative and qualitative research report into attitudes, behaviours and use. 2008, Office of Communications, UK London.

7. Tong, S.T., et al., Too much of a good thing? The relationship between number of friends and interpersonal impressions on Facebook. Journal of Computer - Mediated Communication, 2008. 13(3): p. 531-549.

8. Vergeer, M. and B. Pelzer, Consequences of media and Internet use for offline and online network capital and well -being. A causal model approach. Journal of Computer - Mediated Communication, 2009. 15(1): p. 189-210.

9. Löfgren, O., The nation as home or motel? Metaphors of media and belonging. Sosiologisk Årbok, 2001. 14(1): p. 1-34.

10. Tseng, S.-F. and Y.P. Hsieh, The Implications of Networked Individualism for Social Participation How Mobile Phone, 
E-mail, and IM Networks Afford Social Participation for Rural Residents in Taiwan. American Behavioral Scientist, 2015: p. 0002764215580620.

11. Valkenburg, P.M. and J. Peter, Internet communication and its relation to wellbeing: Identifying some underlying mechanisms. Media Psychology, 2007. 9(1): p. 43-58.

12. Wang, H., V. Chua, and M.A. Stefanone, Social Ties, Communication Channels, and Personal Well-Being A Study of the Networked Lives of College Students in Singapore. American Behavioral Scientist, 2015: p. 0002764215580590.

13. Cacioppo, J.T., et al., Loneliness as a specific risk factor for depressive symptoms: cross-sectional and longitudinal analyses. Psychology and aging, 2006. 21(1): p. 140.

14. Wellman, B., et al., The social affordances of the Internet for networked individualism. Journal of Computer - Mediated Communication, 2003. 8(3): p. 0-0.

15. Quan - Haase, A., J. Cothrel, and B. Wellman, Instant messaging for collaboration: a case study of a high - tech firm. Journal of Computer - Mediated Communication, 2005. 10(4): p. 00-00. 
16. Leung, L., Stressful life events, motives for Internet use, and social support among digital kids. CyberPsychology \& Behavior, 2006. 10(2): p. 204-214.

17. Leung, L., Loneliness, social support, and preference for online social interaction: the mediating effects of identity experimentation online among children and adolescents. Chinese Journal of Communication, 2011. 4(4): p. 381-399.

18. Wellman, B., The network is personal: Introduction to a special issue of Social Networks. Social networks, 2007. 29(3): p. 349-356.

19. Lin, N., Building a network theory of social capital. Connections, 1999. 22(1): p. 28-51.

20. Granovetter, M., Getting a job: A study of contacts and careers. 1995: University of Chicago Press.

21. Lin, N., Social capital: A theory of social structure and action. Vol. 19. 2002: Cambridge university press.

22. Rahn, W.M. and J.E. Transue, Social trust and value change: The decline of social capital in American youth, 1976-1995. Political Psychology, 1998. 19(3): p. 545565. 